\title{
The Nonobvious Basis of Ownership: Preschool Children Trace the History and Value of Owned Objects
}

\author{
Susan A. Gelman, Erika M. Manczak, and Nicholaus S. Noles \\ University of Michigan
}

\begin{abstract}
For adults, ownership is nonobvious: (a) determining ownership depends more on an object's history than on perceptual cues, and (b) ownership confers special value on an object ("endowment effect"). This study examined these concepts in preschoolers $(2.0-4.4)$ and adults $(n=112)$. Participants saw toy sets in which 1 toy was designated as the participant's and 1 as the researcher's. Toys were then scrambled and participants were asked to identify their toy and the researcher's toy. By 3 years of age, participants used object history to determine ownership and identified even undesirable toys as their own. Furthermore, participants at all ages showed an endowment effect (greater liking of items designated as their own). Thus, even 2-year-olds appreciate the nonobvious basis of ownership.
\end{abstract}

Ownership is central to a wide swath of human behavior, ranging from sibling disputes to international diplomacy. Legal, economic, ethical, religious, and social status decisions rest in part on determining ownership (Bloom \& Gelman, 2008; Kalish \& Anderson, 2011; Reb \& Connolly, 2007; Thaler, 1980; Turiel, 2002; Wangdu, Gould, \& Richardson, 2000). From a theoretical standpoint, ownership is of interest because it is a cognitive construction, not materially present in the owned object. As Snare (1972, p. 200) aptly stated, “[A] stolen apple doesn't look any different from any other apple." Moreover, this conceptualized link between person and property is nonobvious in two ways: (a) determining ownership depends more on an object's history than on overt perceptual cues, and (b) ownership confers special value on an object ("endowment effect"). The present investigation examined these concepts in preschoolers and adults.

\section{Ownership and Object History}

A mature concept of ownership entails the central insight that ownership does not reduce to psychological, proximity, or outward perceptual cues. For example, the hat in your closet is yours

The research was supported by NICHD Grant HD-36043 to Gelman. We are grateful to the children and parents who participated in the research. We thank Alex Was, Amanda Markowitz, and Jaime Bortnick for their assistance.

Correspondence concerning this article should be addressed to Susan Gelman, Department of Psychology, University of Michigan, 530 Church St., Ann Arbor, MI 48109-1043. Electronic mail may be sent to gelman@umich.edu. because you originally purchased it. A hat cannot be considered yours just because you like it or want it. Similarly, transfer of ownership can occur without any changes in liking, wanting, or physical possession (e.g., an inherited object is transferred from one person to another, without any physical movement).

One important way to assess ownership is to consider an object's history. This includes a wealth of factors, including: spatiotemporal cues (e.g., a spy might track which of two glasses contains poison by observing its placement over time), traces of history (e.g., a detective might dust for fingerprints), and economic interactions (e.g., buying, swapping, or stealing). Importantly, object history is distinct from other sorts of cues that are relevant to identity, including featural cues (e.g., shape, size), sortal cues (e.g., the small puppy you saw last year might now be a large dog), and causal cues (e.g., a large balloon can transform into a shred of latex). Because ownership relies on object history, and not (solely) featural, sortal, or causal cues, ownership can be said to have a nonobvious basis.

\section{Children's Understanding of Object History as the Basis of Ownership}

Naturalistic observations confirm that ownership is salient to young children (Fasig, 2000; Hay, 2006;

(C) 2012 The Authors

Child Development (c) 2012 Society for Research in Child Development, Inc. All rights reserved. 0009-3920/2012/8305-0021

DOI: $10.1111 /$ j.1467-8624.2012.01806.x 
Levine, 1983; Ross, Tesla, Kenyon, \& Lollis, 1990; Saylor, Ganea, \& Vázquez, 2010) and that children employ adult-like heuristics for identifying owners. For example, children and adults attribute ownership of an object to the first person they see possessing it (Friedman, 2008; Friedman \& Neary, 2008). Moreover, young children understand that ownership is not wholly reducible to current possession. Eisenberg-Berg, Haake, Hand, and Sadalla (1979) and Eisenberg-Berg, Haake, and Bartlett (1981) presented children ( $2-5$ years) with a new toy and studied how they interacted with the toy in the context of other children. Children who heard that the toy belonged only to them defended their possession of the toy more aggressively than children who heard that the toy belonged to their class. Ross (1996; Ross et al., 1990) similarly found that when preschoolers argue with peers or siblings, ownership takes priority over possession. Furthermore, 4-year-olds distinguish between ownership and temporary custody in their interpretations of "have" (Meroni, Gualmini, \& Crain, 2007).

By age 4, children's ownership concepts can be quite sophisticated. For example, 4-year-olds understand that the person who allocates control of an object is its owner (Neary, Friedman, \& Burnstein, 2009). Preschool children also recognize that ownership can transfer as a result of creative labor on the part of an individual (Kanngiesser, Gjersoe, \& Hood, 2010). At the same time, experimental studies reveal developmental changes in children's ownership concepts. Ross (1996) found that 2-yearolds used possession arguments to justify ownership, suggesting possible confusion between these concepts. Similarly, Hay (2006) reported that some preschool children justified ownership by appealing to desire. Other developmental changes are found in how children reason when objects are transferred from one person to another (Blake \& Harris, 2009; Hook, 1993; Kim \& Kalish, 2009; Silberstein, 1998).

In the real world, ownership cues often converge with other factors, such as physical proximity, object desirability, and perceptual and functional features: A child's own toys typically are currently in her possession, are desired by the child, and have distinctive perceptual and functional features. Therefore, precise experimental manipulation is required in order to determine which factors children find most relevant.

\section{Endowment Effect}

A second way in which ownership is nonobvious is that it confers special value, above and beyond an object's material or functional properties. The "hidden value" of ownership is seen in the endowment effect: Simply stipulating an ownership relation, or placing an object in someone's possession (Reb \& Connolly, 2007), evokes heightened preference for that object. For example, if participants receive an object (e.g., a new coffee mug) and then have an opportunity either to keep the original object or to trade it for an object of comparable value (e.g., a new pen), most adults prefer the original object and will not trade unless the new object is of significantly greater value. This phenomenon has been replicated many times (e.g., Beggan, 1992; Gawronski, Bodenhausen, \& Becker, 2007; Kahneman, Knetsch, \& Thaler, 1990; Thaler, 1980). Furthermore, nonhuman primates appear to show an endowment effect with consumable items (food). For example, Brosnan et al. (2007), Kanngiesser, Santos, Hood, and Call (2011), and Lakshminaryanan, Chen, and Santos (2008) employed similar methods (using fruit discs and cereal chunks as goods) to demonstrate that chimpanzees and capuchin monkeys likewise exhibit an endowment effect. This effect is not as strong with nonconsumable goods (e.g., rope), which are less evolutionarily salient.

However, whether and when children show an endowment effect remains unclear. Some children place special value on certain objects owned in infancy (so-called attachment objects; Winnicott, 1969), and anecdotal evidence suggests that even infants may resist swapping the original attachment object for a replacement. Hood and Bloom (2008) find that children 3-6 years of age prefer a beloved object to an exact replica. However, it remains unclear when the endowment effect emerges in development. Harbaugh, Krause, and Vesterlund (2001) found endowment effects in children 510 years of age, although few details are provided concerning the numbers and age range of participants at each age. In an unpublished conference presentation, Martin, Barrett, and Rosser (2005) reported an endowment effect among sixth graders. In contrast, Lucas, Wagner, and Chow (2008) found that only one third of 4-year-olds showed an endowment effect, and overall performance was inconclusive (0.91 trades of 2 possible; M. Lucas, personal communication). Thus, few strong conclusions can be drawn about endowment effects in children, particularly in children below age 5 .

Another open question is whether endowment effects concern object types or object tokens. The endowment effect has nearly always been tested with objects of distinct types (e.g., after being given 
a mug, what is the likelihood that she will trade it for a pen?) rather than with objects of the same type (e.g., trading one mug for another). Thus, it is not clear whether the endowment effect attaches to particular objects (the key prediction if ownership increases the value of the owned object) or instead only to contrasting types of objects. For example, one could increase one's valuation of mugs, without necessarily judging that a particular mug carries special traces of its history. Indeed, there is also evidence that owning one object of Type $X$ increases adults' valuation of other objects of Type X (Morewedge, Shu, Gilbert, \& Wilson, 2009).

\section{Present Studies}

The present studies were designed to test when children understand ownership as a nonobvious attribute, by examining two concepts: (a) that ownership rests on object history rather than observable features (Experiment 1) and (b) that ownership increases the value of an object (Experiment 2). Preschool children and adults received a simple task in which they were first given verbal cues about ownership (e.g., "This is yours; this is mine") and then were asked to determine which of a set of toys is theirs (Experiment 1) and which of a set of toys they like best (Experiment 2). In order to attend to object history, participants had to track the unique identity of the owned objects as they moved through space and time. Object history cues at times competed with cues regarding object appearance and object value.

Three kinds of item sets were included: (a) Identical sets. For these sets, the three toys are perceptually and functionally equivalent (e.g., three identical toy parrots). These sets pit perceptual and functional cues against object history. If children judge ownership on the basis of perceptual and functional relevance, then on this set they should not bother to track which specific item is theirs, assuming that any equivalent item will suffice. In contrast, if children attach significance to object history in determining ownership and object value, they should track the spatiotemporal path of the objects when making their judgments. (b) Child-plain sets. For these sets, the toy assigned to the child is less desirable than the other two toys (e.g., child-target is a plain styrofoam cone; the researcher-target and foil are colorful toy animals). This set pits desirability against object history. If children judge ownership and value on the basis of desirability, then on this set they should select one of the animals as theirs rather than the cone. In contrast, attention to object history should lead children to select their own object. (c) Varied sets. These items are perceptually and functionally distinct (e.g., toy elephant, toy alligator, toy hippo). This is a baseline control, and tests basic comprehension of the task and ability to remember which item was theirs. Children in all age groups should readily display accurate ownership judgments on such sets.

\section{Experiment 1: Ownership Judgments}

Experiment 1 examines ownership judgments, when object history is placed in conflict with other cues. To adults, the task may seem deceptively simple, as it can be solved simply by tracking (via spatiotemporal cues) which objects are initially labeled yours versus mine. The answer is, in effect, given from the start. Spatiotemporal cues are central to human perception and cognition (Burt \& Sperling, 1981; Michotte, 1946/1963; Navon, 1976), and even infants are highly adept at tracking the identity of individual objects (Spelke, Kestenbaum, Simons, \& Wein, 1995; Xu \& Carey, 1996). By preschool age, children skillfully monitor spatiotemporal cues to judge identity (Gutheil, Gelman, Klein, Michos, \& Kelaita, 2008; Gutheil \& Rosengren, 1996; Hall, 1996; Sorrentino, 2001; Williamson, Jaswal, \& Meltzoff, 2010).

However, it is unknown whether children privilege such information to determine ownership. Children could instead rely on current possession and fail to track the spatiotemporal path of the target object, they could treat ownership as an extension of their own desires and thus select the toy they want rather than the toy they were given, or they could rely on featural cues and thus select randomly when the target object is identical to the foils. In contrast, we predicted that even young children would be highly sensitive to object history. Two-year-olds are of special interest given that many children are only starting to learn the words for ownership relations (yours, mine) at this age (e.g., Hay, 2006; Levine, 1983). Finally, there are very few investigations of ownership concepts in children below 3 or 4 years of age.

A final question is whether this sensitivity, if found, would apply to judgments of self-owned objects only or also to judgments of objects owned by others. For adults, memory for self-owned objects is greater than memory for objects owned by others (Cunningham, Turk, Macdonald, \& Macrae, 2008; van den Bos, Cunningham, Conway, \& Turk, 2010). To the extent that this 
"self-reference effect" is a fundamental way of organizing experience, we might expect to find it displayed in children as well.

\section{Method}

Participants. Participants included twenty-one 2-year-olds (10 girls; 2.0-3.0, $M=2.6$ ), eighteen 3-year-olds (9 girls; 3.3-4.4; $M=3.8$ ), and 18 adults (10 women; 17-21, $M=18.6$ ). Four additional 2-year-olds were dropped: Three were unable to complete the task, and one answered fewer than one third of the test questions. Three additional children were dropped due to experimenter error. Children were recruited from communities in and around a Midwestern university town; most were White. Adults were undergraduates at a large university in the same town, and participated for course credit; $72 \%$ were White.

Materials. Materials included 12 animal toys, 12 food toys, 12 furniture toys, 12 vehicle toys, and 4 "plain" objects (see Table 1 and Figure 1). The nonplain objects were selected to be equivalent in attractiveness, complexity, size, and interest within a domain, whereas the plain objects were selected to be much less attractive, complex, or interesting. For each participant, within each domain, a subset of 8 toys plus 1 of the plain objects were arranged into three item sets of 3 toys each: identical (all three items are identical), participant-plain (participant's object is plain and less desirable than the other two objects), and varied (all three items are perceptually distinct and equivalent in valence).
Three-year-olds and adults received 12 item sets of 3 toys each: For each of the four domains (animal, food, furniture, and vehicle), they received 1 identical set, 1 participant-plain set, and 1 varied set. Two-year-olds received exactly the same item sets, except that the furniture items were excluded, in order to shorten the task to accommodate their shorter attention span, thereby resulting in 9 item sets instead of 12 . The sets were constructed with two primary constraints in mind. First, we counterbalanced which item was assigned to the participant (in the identical and varied sets) and which item was assigned to the researcher (in the identical and participant-plain sets). For example, the animal toy assigned to the participant was hippo, parrot, or tiger (each one third of the time, for the identical and varied sets). Second, the sets were assigned such that no toy appeared in more than one set for any given participant. For example, if one participant received the hippo in the varied animal set, then the hippo could not appear in either the participant-plain animal set or the identical animal set for that participant. There were three assignments of sets to participants, indicated in Table 1 as Assignments 1, 2, and 3. Thus, one third of participants in each age group received Set 1 for all item types (identical, participant-plain, and varied) and domains (animal, food, furniture, and vehicle), one third received Set 2 for all item types and domains, and one third received Set 3 for all item types and domains. In order to counterbalance assignment of toys to sets fully, we kept certain toys constant within a domain: the toy assigned to the participant in the participant-plain set, the toy assigned to the

Table 1

Item Sets in Experiments 1 and 2

\begin{tabular}{lllll}
\hline Domain & \multicolumn{1}{c}{ Set type } & \multicolumn{1}{c}{ Set 1} & \multicolumn{1}{c}{ Set 2} & \multicolumn{1}{c}{ Set 3} \\
\hline Animals & Varied & Hippo, alligator, elephant & Parrot, alligator, elephant & Tiger, alligator, elephant \\
Animals & Participant-plain & Styrofoam cone, tiger, horse & Styrofoam cone, hippo, horse & Styrofoam cone, parrot, horse \\
Animals & Identical & Parrot, parrot, parrot & Tiger, tiger, tiger & Hippo, hippo, hippo \\
Food & Varied & Corn, carrot, grapes & Pepper, carrot, grapes & Tomato, carrot, grapes \\
Food & Participant-plain & Cardboard, tomato, pear & Cardboard, corn, pear & Cardboard, pepper, pear \\
Food & Identical & Pepper, pepper, pepper & Tomato, tomato, tomato & Corn, corn, corn \\
Furniture & Varied & Crib, chair, lamp & Infant seat, chair, lamp & Wardrobe, chair, lamp \\
Furniture & Participant-plain & Wood disk, infant seat, couch & Wood disk, wardrobe, couch & Wood disk, crib, couch \\
Furniture & Identical & Wardrobe, wardrobe, wardrobe & Crib, crib, crib & Infant seat, infant seat, infant seat \\
Vehicle & Varied & Motorcycle, airplane, fire engine & Taxi, airplane, fire engine & Train, airplane, fire engine \\
Vehicle & Participant-plain & Block, train, truck & Block, motorcycle, truck & Block, taxi, truck \\
Vehicle & Identical & Taxi, taxi, taxi & Train, train, train & Motorcycle, motorcycle, motorcycle \\
\hline
\end{tabular}

Note. In each set, the participant-assigned toy is listed first, the researcher-assigned toy second, and the unassigned (foil) toy third. Each participant received one varied, one participant-plain, and one identical set in each domain (either Set 1, Set 2, or Set 3). 


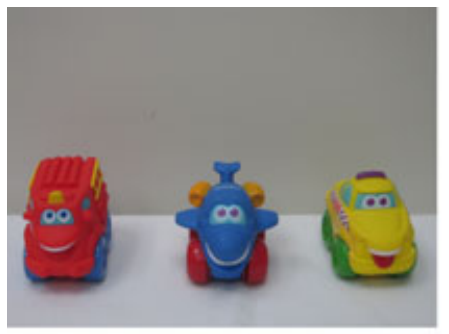

Sample Varied Set

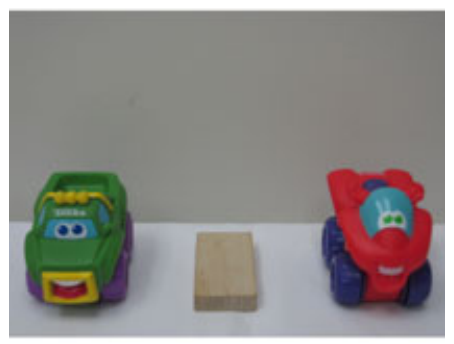

Sample Child-Plain Set

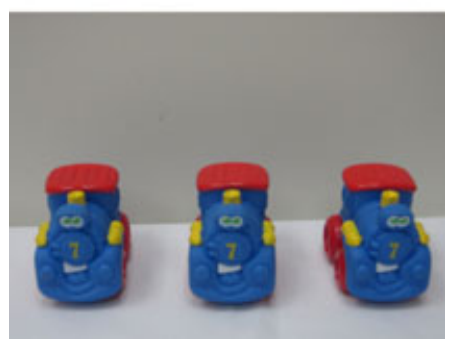

Sample Identical Set

Figure 1. Sample item sets, Experiments 1 and 2.

researcher in the varied set, and the foil (unassigned) toys in the participant-plain and varied sets.

Finally, three mini-containers of Play-Doh (Hasbro, Pawtucket, RI) were presented as the final set for each child participant. Other materials included a white, rectangular plastic tray on which the toys were placed before the test questions were administered, and a brightly colored, "alien" puppet (referred to as "Zippy") that was used for a subset of items (see the next section).

Procedure. The participant and researcher sat at a small table, at right angles from one another (see Figure 2). On each trial, the researcher brought out three objects, one at a time: a self-target (assigned to the participant), an other-target (assigned to the researcher), and a foil (assigned to neither participant nor researcher). (Self and other are designated from the perspective of the participant-not the researcher.) For the self-target, the researcher held up the toy, showed it to the participant, said "This is yours; this is for [participant's name]," and then placed it in front of the participant. For the othertarget, the researcher held up the toy, showed it to (a) Labeling Phase

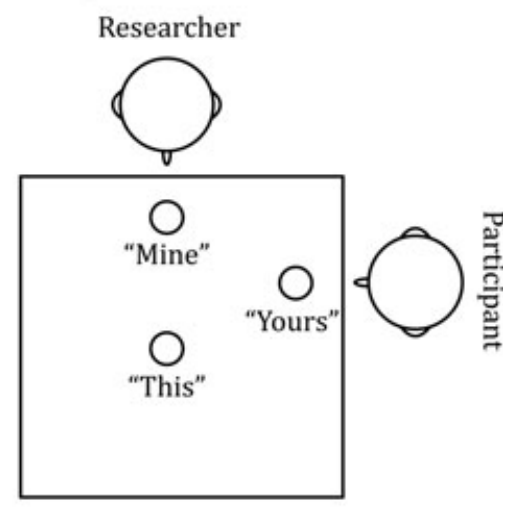

(b) Test Phase

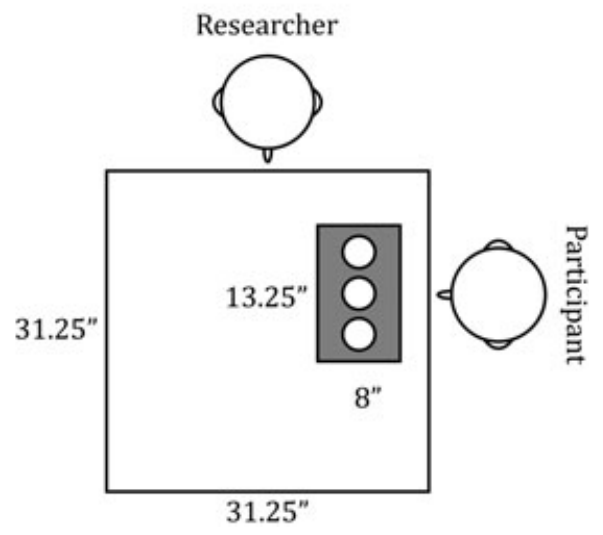

Figure 2. Schematic diagram of aerial view of the experimental setup, during (a) labeling phase and (b) test phase.

Note. Square indicates the table, small circles indicate placement of the toys, and gray rectangle indicates the tray.

the participant, said "This is mine; this is for [researcher's name]," and then placed it in front of herself. For the foil, the researcher held up the toy, showed it to the participant, said "See this; look at this," and then placed it on the table equidistant from the self-target and other-target toys.

Thus, for the self-target and other-target, ownership was cued unambiguously. The foil was also highlighted, but without ownership information. The targets and foil were then placed in a row on a plastic tray as the participant watched, so that spatiotemporal cues were continuously available. Current possession was not available as a dimension on which to select objects, as none of the items were in close proximity to the participant or researcher at the time of test. However, because one end of the tray was closer to the researcher (see Figure 2), we will also examine whether a toy's 
position on the tray may have influenced participants' judgments (see the object position analyses).

Test questions focused on ownership: (a) "Which one is yours?" (self-question) and (b) "Which one is mine?" (other-question). The item sets were ordered such that each group of three contained one set per type (varied, participant-plain, identical), and each group of four contained one trial per domain. Furthermore, we counterbalanced which set participants received first. The order of domains was kept constant across participants (food, animal, vehicle, [furniture]; food, vehicle, animal, [furniture]; animal, [furniture], vehicle, food; as mentioned earlier, furniture items were included for the older children and adults only). Toys within a set were presented in four counterbalanced orders within subjects (self, other, foil; other, self, foil; foil, self, other; foil, other, self). The foil object was never presented between the self-target and the other-target objects, as doing so might make the tracking of the toys more difficult and the distinction between the self-target and other-target objects less clear. Furthermore, this order provides a conservative test of the hypothesis that children can correctly track self-target and other-target objects because correct performance entails avoiding the foil item, and the foil item occurs relatively more often in the more salient positions of first or last.

The toys were then placed on a plastic tray sequentially from left to right using the same order as during initial presentation. The order of test questions (self-question first vs. other-question first) was kept constant across all items for a given participant and counterbalanced between participants, such that approximately half the participants received the self-question first and the other participants received the other-question first.

For the final test trials (two trials apiece for 2-year-olds; three trials apiece for 3-year-olds and adults), we asked participants to infer which toy belonged to a third individual who had not been assigned a toy previously. These questions were included to test whether participants tend to treat ownership as mutually exclusive (i.e., a toy already owned by one person is unlikely to be owned by another). Thus, Zippy the puppet was introduced as wanting to join the game and was placed across the table from the participant. The trials proceeded as before with the addition of a final test question per set to assess Zippy's choices: "Which one is Zippy's?" These trials test whether participants assume that ownership is mutually exclusive (i.e., does Zippy own the unassigned toy?) and were examined separately from the main analyses.

At the end of the session, a final trial was presented to the child participants in order for them to choose a toy to take home. For this trial, children were asked to designate who owned each of three differently colored mini-tubs of play-Doh. This was followed by the standard test protocol. At the end, children were given the play-Doh they had selected as a reward for participating. Responses to this trial were not analyzed.

\section{Results}

Scoring. Participants received a score of 1 each time they selected the relevant assigned object, separately for self- and other-question trials. If the question was "Which one is yours?" selecting the self-assigned object was scored as 1 . If the question was "Which one is mine?" selecting the otherassigned object was scored as 1 . Very rarely $(<1 \%$ of trials), participants selected more than one toy; such trials were scored as 0 . Similarly, if the participant refused to choose (e.g., "I don't know," occurring on $5 \%$, of trials for 2-year-olds, $<1 \%$ for 3-year-olds, and $0 \%$ for adults), they received a score of 0 .

The older participants (3-year-olds and adults) received 24 questions (12 item sets [4 identical, 4 participant-plain, and 4 varied] $\times 2$ questions [self vs. other]), whereas the 2-year-olds received 18 questions (9 item sets [3 identical, 3 participantplain, and 3 varied] $\times 2$ questions [self vs. other]). Within each cell of the design (i.e., each item type and question combination; e.g., self-question for identical trials), scores were summed and could potentially range from 0 to 4 for 3-year-olds and adults, and from 0 to 3 for 2-year-olds. Because 2-year-olds received only 9 trials instead of 12, we adjusted their scores by a constant (4/3) so that they could be analyzed on the same scale as the older age groups. On rare occasion, a session ended early due to child fatigue, thereby resulting in skipped trials (3\% of children's trials); in such cases, the scores were adjusted to account for the missing trial(s). Thus, for all participants, the adjusted scores for a given trial type and question could range from 0 to 4 .

Preliminary analysis. We conducted a preliminary analysis including question order as a factor (Age Group $\times$ Question Order $\times$ Question Type [selfquestion, other-question]), to determine whether performance varied as a function of the order in which the questions were posed (i.e., whether the 
participant received the self-questions first or the other-questions first). There were no significant effects involving question order, so all further analyses collapse over this factor.

Chance values. To calculate the probability of selecting the assigned object by chance, we took into consideration that participants received two questions in each item set. Although all three toys were available for selection on both questions, participants tended not to select the same choice twice. Therefore, whereas chance for the first question is $33 \%(1 / 3)$, chance for the second question depends on which toy was selected on the first question. Specifically, when the assigned object for the second question had not already been selected on the first question, then the chance for the second question was 50\% (one of the two remaining toys). However, when the assigned object for the second question had already been selected on the first question, then the chance for the second question was 0 (as the assigned object no longer remained). Based on participants' choices on the first question, we determined that chance on the second question ranged from $32 \%$ to $50 \%$, varying as a function of age and question (self vs. other). We then averaged the chance values for Questions 1 and 2, within each age group and question. These composite chance levels ranged from $33 \%$ to $42 \%$ (times 4 trials $=1.33-1.68)$. These were the values used in $t$-test comparisons to chance, reported next.

Primary analyses. The scores were entered into a repeated measures analysis of variance (ANOVA), with age group (3: 2-year-olds, 3-year-olds, adults) as a between-subjects variable, and item set (3: identical, participant-plain, varied) and question type (2: self-question, other-question) as withinsubjects variables. The data are presented in Figures 3-5.

We obtained a main effect of age group, $F(2$, $54)=48.55, p<.001, \eta_{\mathrm{p}}{ }^{2}=.64$, indicating that performance improved with age $(M s=2.01,2.98$, and 3.92 at ages 2 years, 3 years, and adults, respectively; all scores differ from one another at $p<.001$, Bonferroni's). There was a main effect of item type, $F(2,108)=5.96, p<.01, \eta_{\mathrm{p}}{ }^{2}=.10$, and an Item Type $\times$ Question interaction, $F(2,108)=9.57, p<$ $.001, \eta_{\mathrm{p}}{ }^{2}=.15$. However, both of these results must be interpreted in light of the significant three-way interaction among item type, question, and age group, $F(4,108)=3.92, p<.01, \eta_{\mathrm{p}}^{2}=.13$.

For adults, performance on the ownership questions did not differ by either item type or question. Scores in each of these cells ranged from $95 \%$ to $100 \%$ accurate, showing adults' excellent capacity (a) Ownership Task (Experiment 1)

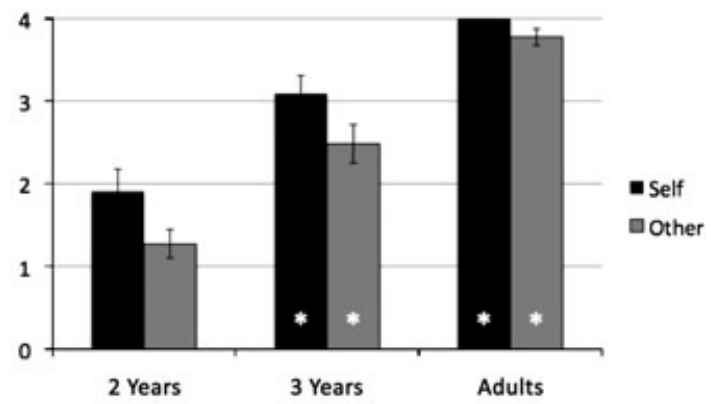

(b) Endowment Task (Experiment 2)

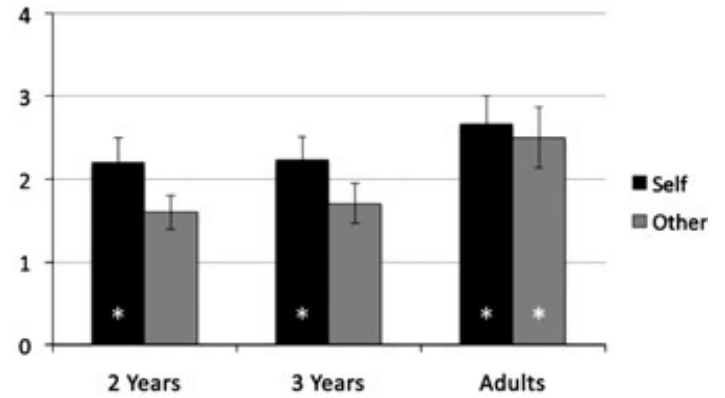

Figure 3. Identical item sets: mean number of trials (out of 4) selecting the assigned object as a function of age group, condition, and question type.

Note. Asterisks indicate values that are significantly above chance.

to identify the owner, across all item sets and both self- and other-questions. All these scores were significantly greater than chance, all $p s<.001$. Threeyear-olds also performed very well across all three item types and both questions (72\%-80\% correct), although performance dropped slightly on the other-question for the identical sets (62\%). This score was significantly lower than the self-question for the identical sets, and significantly lower than the other-question on the varied (control) sets, both ps $<.05$, Bonferroni's. Nonetheless, 3-year-olds selected the appropriate object significantly above chance with all item types and both questions, ts $(17)>3.8, p s \leq .001$.

In contrast to the older two age groups, 2-yearolds had more difficulty with the ownership questions. For the self-question, performance was lower on both the identical and participant-plain sets than on the varied (control) sets, $p s<.05$, Bonferroni's. For the other-question, performance was lower on the identical sets than on the varied sets, $p<.001$. For the identical sets, children in this age group, like the 3-year-olds, performed significantly better when asked about their own toy than the research- 
(a) Ownership Task (Experiment 1)

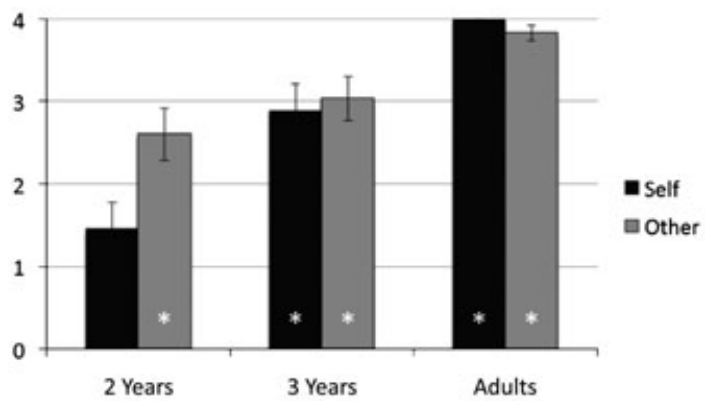

(b) Endowment Task (Experiment 2)

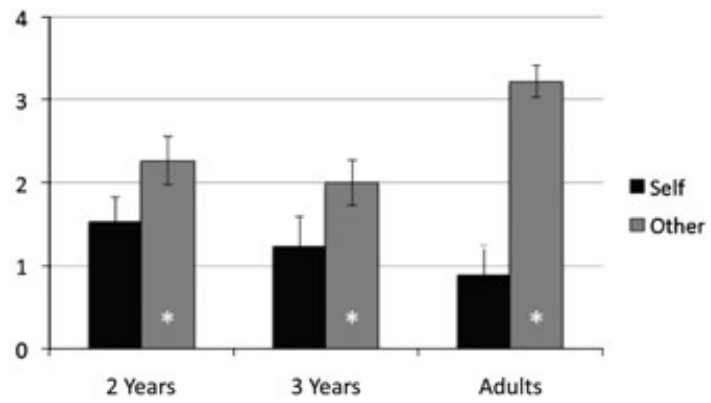

Figure 4. Participant-plain item sets: mean number of trials (out of 4) selecting the assigned object as a function of age group, condition, and question type.

Note. Asterisks indicate values that are significantly above chance.

er's toy, $p<.01$. In contrast, for the participantplain sets, children performed significantly better when asked about the researcher's (nonplain) toy than their own (plain) toy, $p=.001$. Overall, 2-yearolds were significantly above chance on the varied sets for both self- and other-question, ts $(20)>3$, $p \mathrm{~s}<.01$, showing that they understood the task. They were also significantly above chance for the participant-plain set for the other-question, $t(20)=3.80, p=.001$. However, they did not exceed chance for the other-question on the identical set, or for the self-question on the identical or participant-plain sets.

Object position. During test, the toys were equidistant from the participant. However, as noted earlier, the toy at one end of the tray was closest to the researcher. We thus conducted additional analyses to determine whether object location influenced responses. Specifically, we asked: (a) Do participants select the target toy more often when it is closest to the researcher than when it is in either of the other two positions? (b) When given a choice, which do participants select more often: the correct toy or the close toy? (a) Ownership Task (Experiment 1)

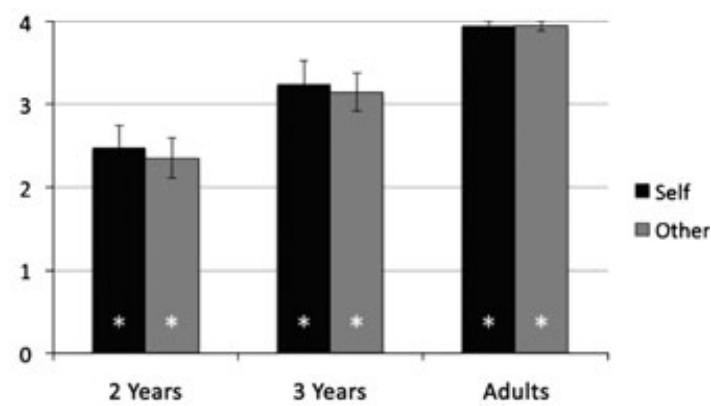

(b) Endowment Task (Experiment 2)

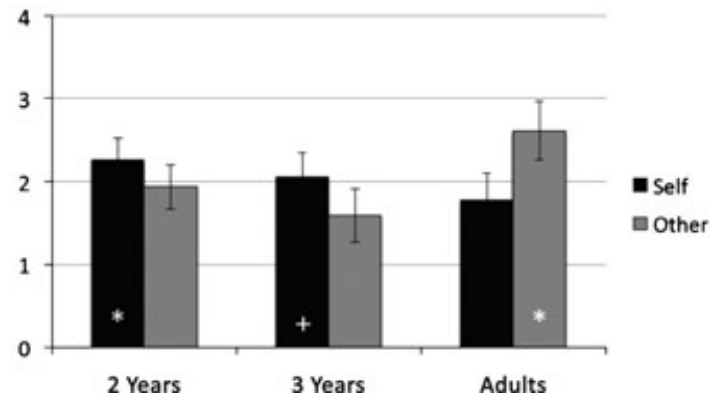

Figure 5. Varied item sets: mean number of trials (out of 4) selecting the assigned object as a function of age group, condition, and question type.

Note. Asterisks indicate values that are significantly above chance. Plus signs $(+)$ indicate trends $(p<.07)$.

To answer the first question, we separated the trials into confounded trials (correct answer was closest to the researcher; $28 \%$ of trials) and unconfounded trials (correct answer was in either of the other positions; $72 \%$ of trials), and then calculated, for each participant and trial type, the proportion of trials on which the target object was selected. We entered these scores into a 3 (age group) $\times 2$ (question type: self, other) $\times 2$ (trial type: confounded, unconfounded) ANOVA. This analysis revealed no significant effects of trial type, indicating that object position had no effect on participants' choices, for either self-questions or other-questions.

To answer the second question, we focused exclusively on trials for which the target toy was in an unconfounded position, such that the correct choice was not the close choice. We computed a difference score, of the proportion of trials on which a participant selected the correct choice, minus the proportion of trials on which he or she selected the close choice (i.e., the toy closest to the researcher). (Participants could also select the choice that was neither correct nor close, although such responses were not relevant to this analysis.) 
The difference scores could range from -1 to +1 , with negative scores indicating selection of the close choice, and positive scores indicating selection of the correct choice. We compared these scores with chance (0). Results indicate that for each age group and each question type (self vs. other), participants selected the correct choice significantly more often than the close choice, all $p s<.05$. Moreover, participants in each age group and question type selected the correct choice above chance, all ps $<.05$. These results converge to indicate that object position does not substantially influence the performance on ownership questions.

Zippy trials. The Zippy trials assess the extent to which participants view ownership as mutually exclusive, namely, that a new individual is likely to own an object that is not already owned by someone else. To test this, we examined how often participants chose the unassigned object as belonging to Zippy. The percentage of Zippy trials on which the unassigned object was selected was 35\%, 57\%, and $50 \%$ at ages 2 years, 3 years, and adults, respectively. This score exceeds chance $(33 \%)$ for the 3-year-olds, $t(15)=3.13, p<.01$, and showed a trend for the adults, $t(17)=1.61, p=.062$, onetailed. However, adults often refused to make a choice (48\% of trials) because a toy was never assigned to Zippy (explaining, e.g., "You didn't say" or "He doesn't have one"). In contrast, 2-yearolds refused to make a choice on only $5 \%$ of trials, and 3-year-olds never did so. When focusing only on trials for which a choice was made, adults' remaining scores average $97 \%$ selection of the unassigned object (greater than chance, $p<.01$ ). These results suggest that when forced to make a choice, 3 -year-olds and adults (but not 2-year-olds) maintain a pattern of mutual exclusivity in their ownership judgments.

Another way to assess this same issue is to examine how often participants selected a toy for Zippy that they did not already assign to another participant (independent of the initial assignment provided by the researcher). For example, a participant who selected the unassigned toy for the self-question, the participant-assigned toy for the other-question, and the researcher-assigned toy for the Zippy question provided mutually exclusive choices, even all three responses were incorrect. By this measure, participants showed mutually exclusive responses for Zippy on a mean of $74 \%$, 98\%, and $100 \%$ of trials at ages 2 years, 3 years, and adults, respectively. We calculated chance as $44 \%$, because of the 27 possible combinations of responses (participant-assigned, researcher-assigned, or unas- signed) to the three questions (yours, mine, Zippy's), 12 combinations were ones for which the Zippy response was mutually exclusive with each of the other two responses. At every age, the degree of mutually exclusivity was significantly greater than chance, $p$ s $\leq .01$.

\section{Discussion}

Experiment 1 demonstrates that 3-year-olds, like adults, construe ownership as a nonobvious property that does not reduce to outward perceptual or functional features. When shown three identical items and told ownership designations for two of them ("This is my toy ... This is your toy"), they track spatiotemporal cues to identify which item is their own. If young children construed ownership simply in terms of the perceptual or functional properties of an object (e.g., "I have a yellow car that can roll'), then they would perform at chance levels on the identical sets. Instead, they consistently selected the toy that had initially been assigned to them. This result cannot be due to the owned item receiving special emphasis, because all three toys were highlighted during the teaching phase. It is also notable that participants spontaneously made use of object history without any special instructions or encouragement from the researcher. Three-year-olds were able to track ownership even when the item assigned to them was undesirable (the participant-plain sets).

In contrast, 2-year-olds had difficulty with both the identical sets and the undesirable sets, tending to select at chance on the identical sets and to select one of the more desirable toys on the undesirable sets. The basis of this difficulty is currently unclear. Two-year-olds were able to track which toys they owned when the toys in a set were equivalent but perceptually distinct, showing that they attend to ownership information and understood the task. Perhaps they undergo conceptual change in their understanding of ownership (at first thinking that it reduces to perceptual features or desirability). However, they instead may have difficulty inhibiting the response to select a more attractive toy, or insufficient motivation not to choose the more attractive toy. Further research would be needed to determine whether this is a conceptual error or a performance error, but at the least this result shows developmental change in the power of original possession when it conflicts with desirability.

Interestingly, children as well as adults were sensitive to the ownership of objects assigned to 
another person (i.e., the researcher). By 2 years of age, they appropriately identified the researcher as the owner of the toys she had assigned to herself, for the participant-plain and varied sets, and by 3 years of age, they did so even when all three items in a set were identical. Thus, young children consider object history to determine ownership, even for nonself owners.

Although performance was excellent overall for both self- and other-questions, the child participants were better at tracking ownership for items assigned to themselves than for items assigned to the researcher, for the identical sets. These findings fit with Cunningham et al.'s (2008) work showing a memory advantage for self-owned items. We speculate that participants are more motivated to encode and remember information regarding their own possessions than those of others. That this effect appears in 2-year-olds suggests it is a fundamental bias.

Finally, participants showed a mutual exclusivity bias concerning ownership, rarely assigning an object to Zippy that had already been assigned to another owner. Mutual exclusivity is a principle that young children adhere to in their word extensions (Markman, 1989; Markman, Wasow, \& Hansen, 2003), and it is notable that this same principle applies outside the realm of labeling.

Altogether, the results of Experiment 1 suggest that children as young as 3 years of age understand that ownership is rooted in object history and not overt perceptual or functional cues. In Experiment 2 , we examine another nonobvious feature of ownership, namely, that owned objects have special value.

\section{Experiment 2: Endowment Effect}

Experiment 2 tests the endowment effect by assigning objects to owners (as in Experiment 1) and then asking participants which item they prefer. In contrast to prior studies of the endowment effect, we directly manipulated whether same kind or different kind of objects are considered. Another major difference from prior work is that we simply asked for liking judgments ("Which one do you like best?"), whereas prior studies of the endowment effect made use of bargaining tasks, in which a participant was asked whether they wish to trade an owned object for another object. Although both methods are valid and useful, the liking task more directly assesses the evaluation of owned objects.

\section{Method}

Participants. Participants included twenty 2-yearolds (11 girls; 2.2-2.9, $M=2.6$ ), seventeen 3-yearolds (9 girls; 3.1-4.4, $M=3.8$ ), and 18 adults (12 women; $17-21, M=18.3$ ). Children were recruited from communities in and around a Midwestern university town; most were White. Adults were undergraduates at a large university in the same town who participated for course credit; $67 \%$ were White. One additional 2-year-old was dropped for answering fewer than one third of the test questions. Seven additional children were dropped due to experimenter error.

Materials. The materials were identical to those of Experiment 1.

Procedure. The procedure was identical to that of Experiment 1 except that the questions asked for liking judgments rather than ownership judgments. Thus, participants were asked: (a) "Which one do you like best?" (self-question) and (b) "Which one do I like best?"' (other-question).

\section{Results}

Scoring. Participants received a score of 1 each time they selected the relevant assigned object, separately for self- and other-question trials. If the question was "Which one do you like best?" selecting the self-assigned object was scored as 1 . If the question was "Which one do I like best?" selecting the other-assigned object was scored as 1 . Very rarely ( $<1 \%$ of trials), participants selected more than one toy. Such trials were scored as 0. Similarly, when the participant refused to choose (e.g., "I don't know," occurring on $5 \%$ of trials for 2-year-olds, $0 \%$ for 3-year-olds, and $6 \%$ for adults), they received a score of 0 . Scores were summed and adjusted as in Experiment 1 . There were no skipped trials.

Chance values were calculated as in Study 1.

Preliminary analysis. We conducted a preliminary analysis including question order as a factor (Age Group $\times$ Question Order $\times$ Question Type [self vs other]) to determine whether performance varied as a function of the order in which the questions were posed (i.e., self-questions first vs. other-questions first). There were no significant effects involving question order, so all further analyses collapse over this factor.

Primary analyses. The primary question was whether participants would prefer the toy that was owned. This is tested most directly by comparing responses to the self-question with chance (1.33). Both 2- and 3-year-olds selected the self-assigned 
objects above chance on the identical sets-2-yearolds: $t(19)=2.4, p s<.05 ; 3$-year-olds: $t(16)=2.7$, $p<.05-$ and the varied sets-2-year-olds: $t(19)=3.0$, $p<.01$; 3-year-olds: $t(16)=2.0, p=.06$-but not the participant-plain sets $(p s>.50)$. Adults also selected the self-assigned objects above chance on the identical sets, $t(17)=3.3, p<.01$, but not on the varied or participant-plain sets. Thus, all age groups showed an endowment effect for identical sets, and children showed an endowment effect for varied sets.

Responses to the other-question could reflect either of two beliefs: (a) that the researcher is subject to an endowment effect or (b) that initial assignment of the toys reflected the researcher's preferences (i.e., she assigned her favorite toys to herself). For the other-question, 2- and 3-year-olds were above chance for participant-plain sets only-2-year-olds: $t(19)=2.8, p<.05$; 3-year-olds: $t(16)=2.5, p<.05$ - and adults were above chance on all three types of sets-ts $(17)>2.9, p s<.01$. Thus, adults consistently assume that the researcher will prefer the toy that she assigned to herself, whereas children primarily assume that the researcher would prefer her own toy on the participant-plain sets only (perhaps due to avoidance of the plain object).

In order to examine how performance changed as a function of age, item set, and question type, the scores were entered into a repeated measures ANOVA, with age group (3: 2-year-olds, 3-yearolds, adults) as a between-subjects variable, and item set (3: identical, participant-plain, varied) and question type (2: self-question, other-question) as within-subjects variables. The data are presented in Figures 3-5.

There was a main effect of question, $F(1,52)=$ $5.29, p<.05, \eta_{\mathrm{p}}{ }^{2}=.09$, although this must be interpreted within two higher-order interactions. A Question $\times$ Age Group interaction, $F(2,52)=8.28$, $p=.001, \eta_{\mathrm{p}}{ }^{2}=.24$, indicated that adults had higher scores for other- than self-questions, $p<.001$, but the other ages did not. As noted earlier, adults may have made the rational inference that the researcher chose to assign herself the objects that she liked the best. There was also a Question $\times$ Item Type interaction, $F(2,104)=38.67, p<.001, \eta_{\mathrm{p}}^{2}=.43$. For identical items, self-questions were higher than other-questions, $p<.01$, indicating an endowment effect for items assigned to the self. For participantplain items, other-questions were higher than selfquestions, $p<.001$, indicating avoidance of the plain items. For varied items, there were no selfother differences.
Position analyses. As in Experiment 1, we first separated the trials into confounded $(28 \%)$ and unconfounded $(72 \%)$, and then calculated, for each participant and trial type, the proportion of trials on which the assigned toy was selected. We conducted a 3 (age group) $\times 2$ (question type: self, other) $\times 2$ (trial type: confounded, unconfounded) ANOVA. The only significant effect involving trial type was a Trial Type $\times$ Question Type interaction, $F(1,50)=23.17, p<.001, \eta_{\mathrm{p}}{ }^{2}=.32$. For other-questions, participants were more likely to pick the assigned toy when it was confounded than unconfounded $(73 \%$ vs. $53 \%, p<.001)$, indicating that participants used proximity to the researcher as one cue regarding the researcher's preferences. In contrast, for self-questions, participants were more likely to pick the assigned toy when it was unconfounded than confounded ( $51 \%$ vs. $40 \%, p<.01$ ).

As in Experiment 1, we then focused exclusively on trials for which the target toy was in an unconfounded position. For self-questions, participants in all age groups preferred the assigned toy over the toy that was close to the researcher (difference score $M s=.35, .26$, and .27 at 2 years, 3 years, and adults, respectively; all $p \mathrm{~s}<.05)$, and selected the assigned toy significantly above chance ( $p s \leq .001$ ). For the other-question, adults selected the assigned toy over the close toy $(p<.001)$, and greater than chance $(p<.001)$, whereas children showed preference for neither the assigned nor the close toy. (Difference scores for the other-toy selections were $.10,-.01$, and .52 at ages 2 years, 3 years, and adults, respectively.) Thus, object position had relatively little effect on performance.

Zippy trials. The Zippy trials assess the extent to which participants assume that preferences are mutually exclusive, namely, that a new individual is likely to prefer an object that is not already owned by someone else. To assess this, we examined how often participants chose the unassigned object as one that Zippy likes best. The percentage of Zippy trials on which the unassigned object was selected was 52\%, $44 \%$, and $50 \%$ at ages 2 years, 3 years, and adults, respectively. These scores do not exceed chance (33\%) at any age, although they are borderline significant at age 2 years $(p=.059)$ and adults $(p=.054)$.

A different way to assess mutual exclusivity of preferences is to examine how often participants selected a toy for Zippy that they did not already select for another participant (regardless of the researcher's initial assignment). Thus, we tallied, for each item set, how often participants selected a different toy for Zippy than for either of the other 
two questions (self and other). The mean rates of mutually exclusive responses were $83 \%, 100 \%$, and $71 \%$ at ages 2 years, 3 years, and adults, respectively. These scores were all significantly greater than chance $(44 \%), p s<.05$.

Comparisons with Experiment 1. Although the primary purpose of Experiment 2 was to assess whether owned objects have special value (endowment effect), the data also permit us to ask whether and when the ownership judgments in Experiment 1 differ from mere liking. In order to assess this question, we conducted a set of analyses comparing responses across the two experiments: ownership (Experiment 1) and liking (Experiment 2). Specifically, we conducted a 3 (age group: 2 years, 3 years, adults) $\times 2$ (task: ownership, liking) $\times 3$ (item type: identical, participant-plain, varied) $\times 2$ (question: self, other) repeated measures ANOVA. We report only those effects involving task.

Results indicate numerous significant effects involving task (a main effect of task; Item Type $\times$ Task; Question $\times$ Task; Age $\times$ Task; Question $\times$ Age $\times$ Task; Item $\times$ Question $\times$ Task), all subsumed under a significant four-way interaction (Question $\times$ Age $\times$ Item $\times$ Task), $F(4,212)=4.96, p=.001$, $\eta_{\mathrm{p}}{ }^{2}=.09$. Two-year-olds showed no significant task differences ( $p$ s ranging from .24 to .86). In contrast, 3 -year-olds and adults consistently selected the assigned toys more often in Experiment 1 (ownership task) than in Experiment 2 (liking task). For 3 -year-olds, $p$ values ranged from .026 to $<.001$; for adults, $p$ values were all $\leq .001$, with the exception of the other-question for participant-plain sets, where $p=.098$. Overall, then, for 3-year-olds and adults, ownership judgments are distinct from preferences.

\section{Discussion}

Experiment 2 was designed to examine whether children and adults prefer objects that they own (endowment effect). We found that children as young as 2 years of age show greater liking of objects to which they are assigned as owners. For example, the objects in the identical sets were physically indistinguishable, yet participants in all age groups indicated that they most liked the object that had been assigned to them. Similarly, for the varied sets, 2-year-olds indicated that they most liked the object that had been assigned to them. This is a striking result, and it is important to note that other patterns were certainly possible. For example, children could have shown preference for the researcher's toy, out of envy or social referenc- ing. Or, children may have made their liking judgments exclusively on the basis of the material properties of the objects. Instead, however, the nonvisible property of ownership guided their preference judgments.

The only items for which performance did not exceed chance were the participant-plain sets. However, it is perhaps not surprising that participants did not select these items above chance, given the baseline undesirability of these toys. Therefore, in order to provide another assessment of the extent to which even the plain items might have been enhanced in desirability, we asked a separate group of 19 undergraduates and 14 children (2.34.3; mean age $=3.5$ ) to choose which toy they liked best, given the participant-plain sets. The toys and test questions were identical to those of Experiment 2; the only difference was that no ownership information was provided beforehand. As expected, in the absence of ownership information, preference for the plain choice was quite low at both ages (Ms $=23 \%$ and $4 \%$ for children and adults, respectively; both scores are significantly below chance, $p s \leq .05)$. For adults, this rate was significantly lower than the rate at which adults selected the plain item when ownership information was provided (22\% in the self-question of Experiment 2), $t(35)=2.07, p<.05$, indicating that liking of even the plain item was enhanced by first assigning it to the participant. For children, however, the score in the absence of ownership information did not significantly differ from the score in the presence of ownership information (34\%), suggesting that for young children, the endowment effect may not be powerful enough to override clear a priori preferences.

Nonetheless, the above-chance performance on the identical item sets (at all ages) and the varieditem sets (for 2- and 3-year-olds), as well as the above-baseline performance on the plain sets (for adults) all argue that ownership confers special value on objects, across the life span. This finding extends beyond prior work in demonstrating that preference is for the particular object assigned (not just for that type of object). These data are consistent with both an endowment effect and a mere ownership effect.

When asked about the researcher's preferences, only adults consistently assume that the researcher will prefer the toy that she assigned to herself. Children, in contrast, primarily assume that the researcher would prefer her own toy only on the participant-plain sets only (perhaps because they assume that the researcher will not like the plain 
object). These data suggest that the endowment effect in children is specific to self-judgments. Adults may expect that others will display an endowment effect, or they may simply assume that the researcher assigned the most preferred item to herself to begin with. More research would be needed to tease apart these two explanations.

The most striking developmental change concerned the comparison between the two experiments. Three-year-olds and adults distinguish ownership from likability, reporting that they owned objects even when they did not like them (e.g., the participant-plain items). In contrast, 2-year-olds show no difference between the ownership task (Experiment 1 ) and the endowment task (Experiment 2). In other words, 2-year-olds conflate ownership with desirability, thus failing to grasp that a toy they do not like actually belongs to them. This result means either that liking is guiding toddlers' ownership judgments (i.e., the two concepts are inseparable) or that ownership is guiding their liking judgments (i.e., a strong endowment effect). Either way, the result indicates an endowment effect in 2-year-olds, as they select their own object above chance on the liking judgment.

\section{General Discussion}

These data speak to two primary issues in the literature: What cues do young children use to determine ownership? And, to what extent does ownership confer an endowment effect? We discuss each of these issues in turn.

\section{Cues to Determining Ownership}

A mature concept of ownership includes an understanding that proximity, perceptual or functional features, and desirability, although potent factors, cannot by themselves determine who owns what. In other words, ownership is an invisible quality that can be traced by consideration of object history rather than by inspection of the properties of the object. Given the centrality of object history, it becomes particularly important to track where an object moves over time.

The present studies demonstrate that children as young as 3 years of age spontaneously attend to object history to determine ownership. They do not conform to the belief that any object that is equivalent in appearance and function to theirs can be considered their own; rather, they track an object's path through time and space, taking care to notice and remember which of three identical items is their own.

In addition to this main finding, there were two additional results that further shed light on children's early ownership judgments. First, participants in all age groups treated ownership as mutually exclusive: When asked which object Zippy owned, in the absence of any prior information, they guessed that Zippy would own the object that was not owned by anyone else. Even 2-yearolds showed clear evidence for this assumption. This result suggests that children may understand that ownership entails considering not just the history of a person (e.g., Zippy) with an object (e.g., the foil), but also what other individuals in the context own (in this case, that the researcher and participant already owned the other objects).

The second additional finding concerned selfother differences. On the ownership task, both 2- and 3-year-olds performed significantly better on the self-questions than the other-questions. This parallels prior findings with adults (Cunningham et al., 2008; van den Bos et al., 2010). Further studies would be required to determine the source of this effect; for example, it could be due to differences in initial attention, encoding, or memory.

\section{Ownership and the Endowment Effect}

Ownership is nonobvious in a second respect as well; namely, ownership in and of itself adds value to an object (the endowment or mere ownership effect). The present data are new in several ways. These data are the first to demonstrate an endowment effect in children 2 and 3 years of age. Prior to this set of experiments, little was known about endowment effects in children below age 5 . These younger children provide additional insight into the developmental roots of this behavior. The present findings suggest that positive evaluation of and preference for one's own possessions is a basic cognitive disposition, even before children have experience with conventional economic transactions.

These studies also demonstrate that special value adheres to the particular individual object that is owned. We directly manipulated whether samekind or different-kind objects were presented, in contrast to prior work, which typically tested participants' valuation of either the very object they possess or an object of a different kind. The results we obtained (that participants prefer the very object they had been given) suggest that history holds special significance for an object (Rozin \& Nemeroff, 1990). 
These studies also are the first we know of to examine participants' beliefs concerning the value of owned objects to others (i.e., non-selfjudgments). However, the mechanism by which another's preferences reflect ownership likely differ from the mechanism by which self-preferences reflect ownership, at least as measured here. In the current studies, because the researcher was the one who determined which person owned which toy, it could be assumed that the researcher assigned herself the toys she liked best. In other words, the researcher's "liking" judgment may have determined the ownership assignment in the first place. In contrast, the participant's "liking" judgment was a consequence of the ownership assignment. In future research, it would be interesting to vary how objects are assigned to owners (e.g., does the participant assign the objects, does the researcher assign the objects, or is object assignment determined randomly?), in order to disentangle initial preferences from preferences that are a consequence of ownership.

Different theoretical accounts have been offered for the endowment effect (e.g., loss aversion vs. added value to an owned object; Beggan, 1992; Morewedge et al., 2009). The present data support the interpretation that ownership confers added value to an object. Because we did not use a barter task, there was no possibility for loss aversion. Thus, it may be that loss aversion typically also has an effect, but from the current research we know that it is not required in order to obtain an endowment effect.

\section{Conclusions}

The present studies suggest that by early preschool, children construe ownership as nonobvious, in two major respects: (a) By age 3 years, ownership is a relation that cannot be discerned by outward perceptual or functional features, or an assessment of who is currently in possession of the owned object. Instead, it relies on the history of an object. (b) By age 2 years, ownership confers special (again, invisible) value to an object for the owner. By honoring these principles, young children possess a basic and early-emerging tendency to treat objects as carrying special traces of their past. Moreover, this tendency is apparent without any explicit instructions or encouragement from the researcher, suggesting that children spontaneously attend to and track the nonobvious basis of ownership.
In future research, it would also be valuable to examine other respects in which ownership may link to nonobvious bases or consequences. For example, object value reflects a wealth of nonobvious properties, including rareness or inaccessibility (e.g., moon dust), symbolic value (e.g., a scouting uniform indicates group affiliation; a Ferrari indexes social standing), or links to famous or beloved individuals (e.g., handwritten Beatles lyrics; Dittmar, 1992; Frazier, Gelman, Wilson, \& Hood, 2009; Porter, 2011). Ownership may also have consequences for mental state attributions (e.g., what owners vs. nonowners know about the objects in question).

Ownership is one potent means of demonstrating this sensitivity to object history, but it is not the only one. This capacity apparently underlies other early emerging childhood abilities as well, including the ability to confer proper names to individuals (Sorrentino, 2001), and psychological essentialism more broadly (Bloom, 2010; Gelman, 2003). Although the capacity to reason about object history seems straightforward, it can sometimes go awry. For example, in Capgras syndrome, people believe that an object or individual has been replaced by an identical imposter (Edelstyn \& Oyebode, 1999). This disorder suggests that a concept of historical continuity can be dissociated from all relevant properties associated with an individual (appearances, behaviors). In future research, it will be important to examine the developmental conditions that foster this understanding.

\section{References}

Beggan, J. (1992). On the social nature of nonsocial perception: The mere ownership effect. Journal of Personality and Social Psychology, 62, 229-237.

Blake, P. R., \& Harris, P. L. (2009). Children's understanding of ownership transfers. Cognitive Development, 24, 133-145.

Bloom, P. (2010). How pleasure works: The new science of why we like what we like. New York: Norton.

Bloom, P., \& Gelman, S. A. (2008). Psychological essentialism in selecting the 14th Dalai Lama. Trends in Cognitive Sciences, 12, 243.

Brosnan, S. F., Jones, O. D., Lambeth, S. P., Mareno, M. C., Richardson, A. S., \& Schapiro, S. J. (2007). Endowment effects in chimpanzees. Current Biology, 17, 17041707.

Burt, P., \& Sperling, G. (1981). Time, distance, and feature trade-offs in visual apparent motion. Psychological Review, 88, 171-195.

Cunningham, S., Turk, D., Macdonald, L., \& Macrae, C. (2008). Yours or mine? Ownership and memory. Con- 
sciousness and Cognition: An International Journal, 17, 312-318.

Dittmar, H. (1992). The social psychology of material possessions. New York: St. Martin's Press.

Edelstyn, N., \& Oyebode, F. (1999). A review of the phenomenology and cognitive neuropsychological origins of the Capgras syndrome. International Journal of Geriatric Psychiatry, 14, 48-59.

Eisenberg-Berg, N., Haake, R. J., \& Bartlett, K. (1981). The effects of possession and ownership on the sharing and proprietary behaviors of preschool children. MerrillPalmer Quarterly, 27, 61-68.

Eisenberg-Berg, N., Haake, R., Hand, M., \& Sadalla, E. (1979). Effects of instructions concerning ownership of a toy on preschoolers' sharing and defensive behaviors. Developmental Psychology, 15, 460-461.

Fasig, L. G. (2000). Toddlers' understanding of ownership: Implications for self-concept development. Social Development, 9, 370-382.

Frazier, B. N., Gelman, S. A., Wilson, A., \& Hood, B. (2009). Picasso paintings, moon rocks, and handwritten Beatles lyrics: Adults' evaluations of authentic objects. Journal of Cognition and Culture, 9, 1-14.

Friedman, O. (2008). First possession: An assumption guiding inferences about who owns what. Psychonomic Bulletin E Review, 15, 290-295.

Friedman, O., \& Neary, K. R. (2008). Determining who owns what: Do children infer ownership from first possession? Cognition, 107, 829-849.

Gawronski, B., Bodenhausen, G., \& Becker, A. (2007). I like it, because I like myself: Associative self-anchoring and post-decisional change of implicit evaluations. Journal of Experimental Social Psychology, 43, 221232.

Gelman, S. A. (2003). The essential child: Origins of essentialism in everyday thought. New York: Oxford University Press.

Gutheil, G., Gelman, S., Klein, E., Michos, K., \& Kelaita, K. (2008). Preschoolers' use of spatiotemporal history, appearance, and proper name in determining individual identity. Cognition, 107, 366-380.

Gutheil, G., \& Rosengren, K. S. (1996). A rose by any other name: Preschooolers' understanding of individual identity across name and appearance changes. British Journal of Developmental Psychology, 14, 477498.

Hall, D. G. (1996). Preschoolers' default assumptions about word meaning: Proper names designate unique individuals. Developmental Psychology, 32, 177-186.

Harbaugh, W. T., Krause, K., \& Vesterlund, L. (2001). Are adults better behaved than children? Age, experience, and the endowment effect. Economics Letters, 70, 175-181.

Hay, D. F. (2006). Yours and mine: Toddlers' talk about possessions with familiar peers. British Journal of Developmental Psychology, 24, 39-52.

Hood, B., \& Bloom, P. (2008). Children treat attachment objects as irreplaceable individuals. Cognition, 106, 455462.
Hook, J. (1993). Judgments about the right to property from preschool to adulthood. Law and Human Behavior, 17, 135-146.

Kahneman, D., Knetsch, J. L., \& Thaler, R. H. (1990). Experimental tests of the endowment effect and the Coase Theorem. Journal of Political Economy, 98, 1325-1348.

Kalish, C. W., \& Anderson, C. D. (2011). Ownership as a social status. In O. Friedman \& H. Ross (Eds.), Children's ownership (pp. 65-77). San Francisco: New Directions in Child and Adolescent Development.

Kanngiesser, P., Gjersoe, N., \& Hood, B. M. (2010). The effect of creative labor on property-ownership transfer by preschool children and adults. Psychological Science, 21, 1236-1241.

Kanngiesser, P., Santos, L. R., Hood, B. M., \& Call, J. (2011). The limits of endowment effects in great apes (Pan paniscus, Pan troglodytes, Gorilla gorilla, Pongo pygmaeus). Journal of Comparative Psychology, 125, 436-445.

Kim, S., \& Kalish, C. (2009). Children's ascriptions of property rights with changes of ownership. Cognitive Development, 24, 322-336.

Lakshminaryanan, V., Chen, M. K., \& Santos, L. R. (2008). Endowment effect in capuchin monkeys (Cebus apella). Philosophical Transactions of the Royal Society B: Biological Sciences, 363, 3837-3844.

Levine, L. E. (1983). Mine: Self-definition in 2-year-old boys. Developmental Psychology, 19, 544-549.

Lucas, M., Wagner, L., \& Chow, C. (2008). Fair game: The intuitive economics of resource exchange in four-year olds. Journal of Social, Evolutionary, and Cultural Psychology, 2, 74-88.

Markman, E. (1989). Categorization and naming in children: Problems of induction. Cambridge, MA: MIT Press.

Markman, E., Wasow, J., \& Hansen, M. (2003). Use of the mutual exclusivity assumption by young word learners. Cognitive Psychology, 47, 241-275.

Martin, S., Barrett, D. W., \& Rosser, R. (2005, May). The girls who gave: A study of the endowment effect in children's donating behavior. Poster presented at the annual conference of the American Psychological Society, Los Angeles.

Meroni, L., Gualmini, A., \& Crain, S. (2007). The strength of the universal quantifier in child language. In A. Belikova, L. Meroni, \& M. Umeda (Eds.), Proceedings of the 2 nd conference on generative approaches to language acquisition North America (GALANA) (pp. 277-285). Somerville, MA: Cascadilla Proceedings Project.

Michotte, A. (1963). The perception of causality (T. Miles \& E. Miles, Trans.) New York: Basic Books. (Original work published 1946).

Morewedge, C., Shu, L., Gilbert, D., \& Wilson, T. (2009). Bad riddance or good rubbish? Ownership and not loss aversion causes the endowment effect. Journal of Experimental Social Psychology, 45, 947-951.

Navon, D. (1976). Irrelevance of figural identity for resolving ambiguities in apparent motion. Journal of 
Experimental Psychology: Human Perception and Performance, 2, 130-138.

Neary, K.R., Friedman, O., \& Burnstein, C.L. (2009). Preschoolers infer ownership from "control of permission." Developmental Psychology, 45, 873-876.

Porter, E. (2011). The price of everything. New York: Portfolio. Reb, J., \& Connolly, T. (2007). Possession, feelings of ownership and the endowment effect. Judgment and Decision Making, 2, 107-114.

Ross, H. S. (1996). Negotiating principles of entitlement in sibling property disputes. Developmental Psychology, 32, 90-101.

Ross, H., Tesla, C., Kenyon, B., \& Lollis, S. (1990). Maternal intervention in toddler peer conflict: The socialization of principles of justice. Developmental Psychology, 26, 994-1003.

Rozin, P., \& Nemeroff, C. (1990). The laws of sympathetic magic: A psychological analysis of similarity and contagion. In J. W. Stigler, R. A. Shweder, \& G. Herdt (Eds.), Cultural psychology: Essays on comparative human development (pp. 205-232). New York: Cambridge University Press.

Saylor, M. M., Ganea, P. A., \& Vázquez, M. D. (2010). What's mine is mine: Twelve-month-olds use possessive pronouns to identify referents. Developmental Science, 14, 859-864.

Silberstein, C. S. (1998). Conceptions of ownership: A study in soft cognitive science. PhD dissertation, Cornell University.

Snare, F. (1972). The concept of property. American Philosophical Quarterly, 9, 200-206.
Sorrentino, C. M. (2001). Children and adults represent proper names as referring to unique individuals. Developmental Science, 4, 399-407.

Spelke, E., Kestenbaum, R., Simons, D., \& Wein, D. (1995). Spatiotemporal continuity, smoothness of motion and object identity in infancy. British Journal of Developmental Psychology, 13, 113-142.

Thaler, R. (1980). Towards a positive theory of consumer choice. Journal of Economic Behavior and Organization, 1, 39-60.

Turiel, E. (2002). The culture of morality: Social development, context, and conflict. New York: Cambridge University Press.

van den Bos, M., Cunningham, S. J., Conway, M. A., \& Turk, D. J. (2010). Mine to remember: The impact of ownership on recollective experience. Quarterly Journal of Experimental Psychology, 63, 1065-1071.

Wangdu, K. S., Gould, B. J., \& Richardson, H. E. (2000). Discovery, recognition, and enthronement of the 14th Dalai Lama: A collection of accounts. Dharamsala, India: Library of Tibetan Works \& Archives.

Williamson, R. A., Jaswal, V. K., \& Meltzoff, A. N. (2010). Learning the rules: Observation and imitation of a sorting strategy by 36-month-old children. Developmental Psychology, 46, 57-65.

Winnicott, D. W. (1969). The child, the family, and the outside world. Baltimore: Penguin.

Xu, F., \& Carey, S. (1996). Infants' metaphysics: The case of numerical identity. Cognitive Psychology, 30, 111-153. 